\title{
Adult Turner syndrome associated with chylous ascites and vascular anomalies
}

\author{
Jonathan Treisman and Francis S. Collins \\ Departments of Internal Medicine and Human Genetics, University of Michigan School of \\ Medicine, Ann Arbor, MI, USA
}

\begin{abstract}
An adult female with Turner syndrome presented with severe lymphedema and chylous ascites. In addition, the patient was found to have a right-sided aortic arch and a left-sided inferior vena cava. Although lymphedema is common in infants with Turner syndrome, it usually resolves in childhood. Chylous ascites in association with Turner syndrome is previously unreported. In this patient, a peritoneo-venous shunt appeared to be beneficial.
\end{abstract}

Received 6 June, accepted for publication 28 October 1986

Key words: Chylous ascites; lymphedema; Turner syndrome; vascular anomalies.

In 1938 Henry Turner described the association of sexual infantilism, webbed neck and cubitus valgus in adult women (Turner 1938). Subsequently, gonadal dysgenesis was defined as part of the syndrome and the characteristic chromosomal abnormality $(45, X)$ was reported (Wilkins \& Fleischmann 1944, Ford et al. 1959). A variety of congenital malformations have been described as Turner stigmata. Lymphedema occurs in $80 \%$ of newborns with Turner syndrome (Hall et al. 1982), but is usually transient. In this report we describe an adult with both lymphedema and chylous ascites. The latter has not previously been reported in association with Turner syndrome.

\section{Material and Methods}

\section{Case Report}

P. S., UMMC \#1154-134-3, was a full term infant, smaller than her siblings at birth weight 3.2 kilograms. Edema was not noted at birth (in Mexico) but appeared in the right lower extremity at age three and subsequently in the left lower and left upper extremities. The edema was not associated with shortness of breath nor cyanosis, and edema of the right upper extremity never developed. At the age of eight, a diagnosis of pulmonary tuberculosis was made and she was treated with isoniazid and ethambutol for one year. Evaluation at age nine revealed no etiology for the edema, but hypertension was noted. Coarctation of the aorta was considered, but blood pressure was equal in all extremities. At age thirteen a karyotype showed $45, X$ and Turner syndrome was diagnosed. Premarin therapy was begun.

At age 25, P.S. experienced a gradual 5 kilogram weight gain and increasing abdominal girth. Examination revealed a 150 centimeter tall, 45 kilogram woman with blood pressure 150/120 (Figure 1). Hypoplastic nails and multiple pigmented nevi were present. She had mild micrognathia 


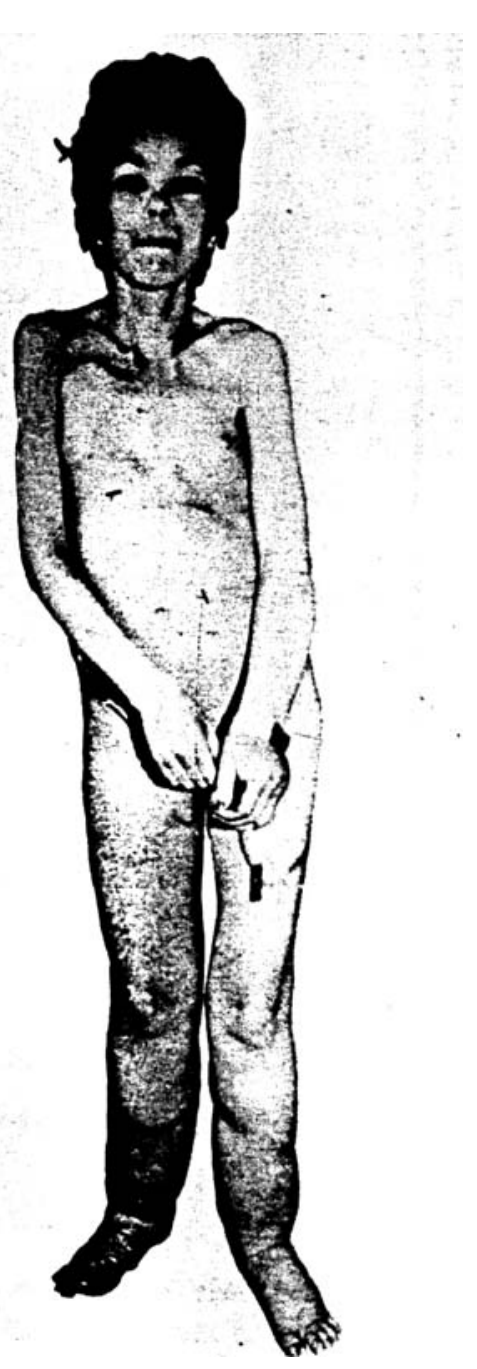

Fig. 1. The patient one week after the Denver shunt. Extreme lymphedema of the lower and right upper extremities is still present, but abdominal girth is substantially decreased. The figure illustrates the patient's widely spaced nipples, absent breast development, and pigmented nevi.

and low set ears, but a normal hairline and normal palate. No thyromegaly was present. A shield chest with broadly spaced nipples was apparent with no breast development. There was dextroscoliosis and an

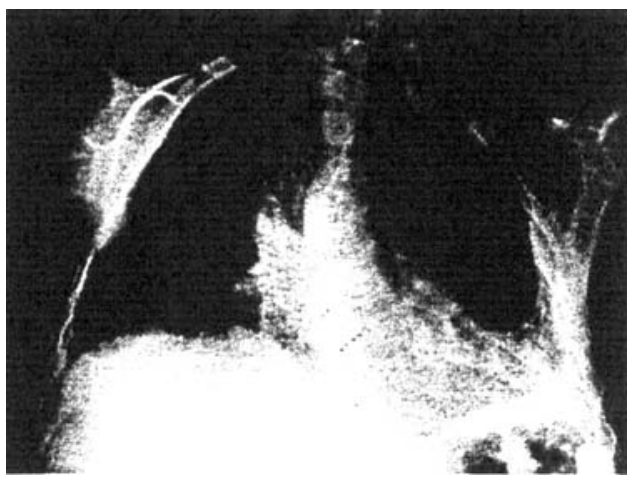

Fig. 2. Chest $X$-ray reveals elevated hemidiaphragms and right aortic arch. Chest wall deformity is evident.

asymmetric pectus carinatum with the sternum displaced to the right. The abdomen was tense and distended with a fluid wave present, and the liver was palpable 3 centimeters below the costal margin with no tenderness, masses, or nodularity. Blood pressure was equal in all four extremities, and marked edema was present in all but the right upper extremity. Laboratory exams included a hematocrit $42.8 \%$, white cell count 6100 , sodium $135 \mathrm{mmol}$, potassium 3.8 mmol, urea nitrogen $19 \mathrm{mg} / \mathrm{dL}$, calcium 7.9 $\mathrm{mg} / \mathrm{dL}$, SGOT $11 \mathrm{U} / \mathrm{mL}$, alkaline phosphatase $128 \mathrm{IU} /$ liter, serum protein $4.3 \mathrm{~g} / \mathrm{dL}$, and albumin $2.2 \mathrm{~g} / \mathrm{dL}$. Thyroid function tests were normal. A chest X-ray revealed a right-sided aortic arch (Figure 2) and abdominal X-ray was consistent with ascites, also revealing a hemivertebra of $L-4$ and lumbarization of S-1 (Figure 3a).

Paracentesis provided milky fluid with protein content $<0.1 \mathrm{~g} / \mathrm{dL}$, glucose $107 \mathrm{mg} /$ $\mathrm{dL}, 270$ leukocytes per mm with $16 \%$ lymphocytes and $82 \%$ histiocytes, triglycerides markedly elevated at $2496 \mathrm{mg} / \mathrm{dL}$, and negative cultures, negative cytology, and no acid-fast bacilli by smear or culture. Computed tomography of the abdomen and chest showed marked ascites, atrophic uterus, a right aortic arch, and bony deformity 


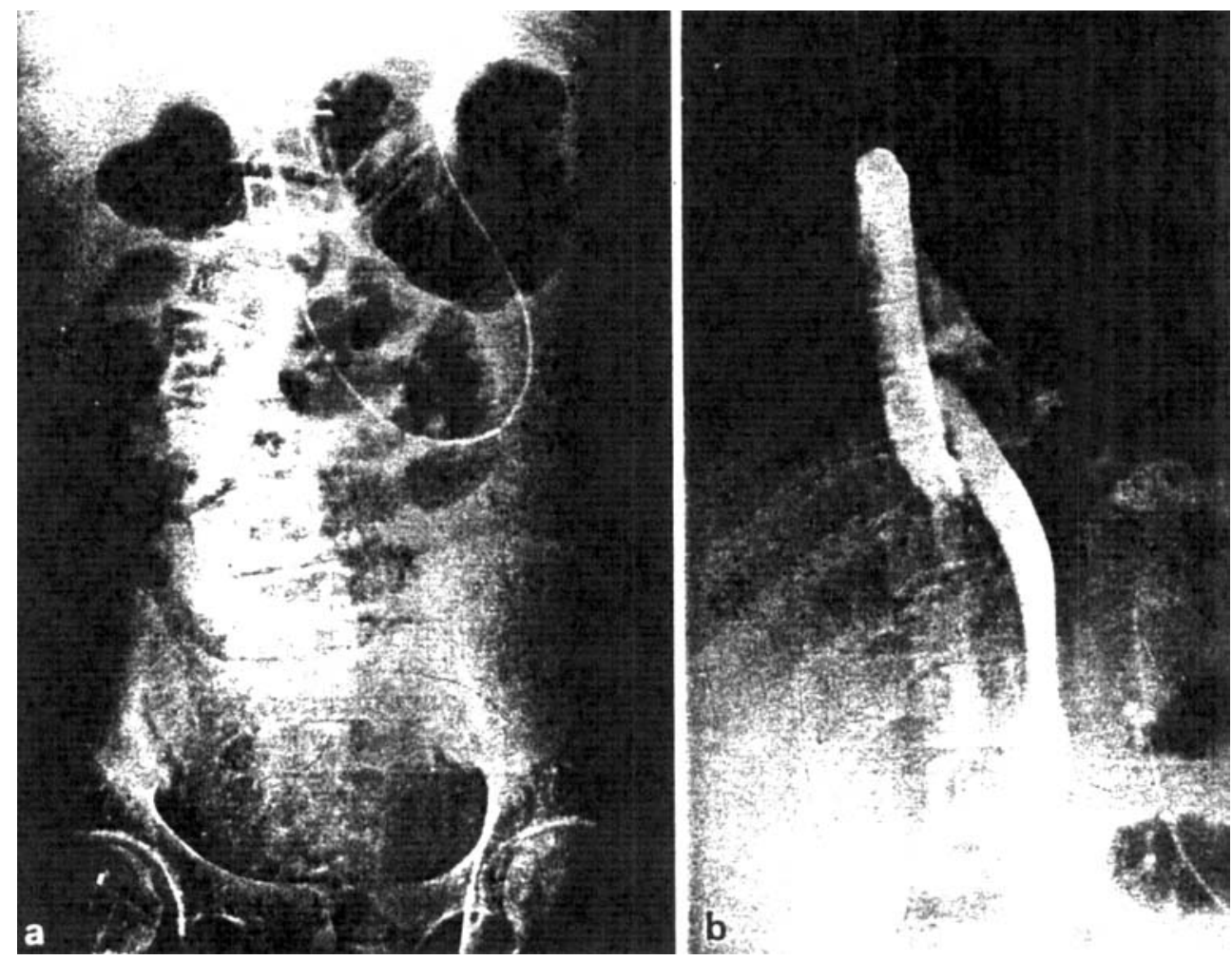

Fig. 3a. Abdominal $X$-ray is consistent with ascites and reveals dextroscoliosis with a hemivertebra at $L-A$ and lumbarization of $\mathrm{S}-1$.

Fig. 3b. Venogram shows the left sided inferior vena cava crossing over into the azygous vein via the hemiazygous vein which arches into the superior vena cava.

of the chest wall. Upper endoscopy was performed with duodenal biopsies showing normal mucosa. Intravenous pyelogram was normal. Venogram was done showing left-sided inferior vena cava with crossover to the right side via the azygous vein (Figure 3b). A repeat G-banded karyotype showed $45, \mathrm{X}$ in 15 cells, with no other rearrangements present.

A short course of low fat diet with supplementary medium chain triglycerides provided no relief and the patient remained dyspneic from her tense ascites. She underwent a Denver peritoneo-venous shunt. Post-operatively a left chylothorax ap- peared but slowly resolved as abdominal girth decreased and the patient became more ambulatory (Figure 1). Nine months post-operatively the patient continues to have marked peripheral lymphedema but abdominal girth is dramatically decreased from that before surgery.

\section{Discussion}

This patient illustrates many of the characteristic stigmata of Turner syndrome (Table 1) as well as some unusual findings. Congenital transient lymphedema which usually 
Table 1

Clinical findings in Turner syndrome*

\begin{tabular}{lr}
\hline Short stature & $100 \%$ \\
Sexual infantilism & $99 \%$ \\
Multiple pigmented nevi & $63 \%$ \\
Shield chest & $55 \%$ \\
Cubitus valgus & $55 \%$ \\
Low hairline & $54 \%$ \\
Short fourth metacarpal & $48 \%$ \\
Abnormal ears & $48 \%$ \\
Hypoplastic nails & $43 \%$ \\
Webbed Neck & $41 \%$ \\
Lymphedema & $36 \%$ \\
Arched palate & $36 \%$ \\
Epicanthal tolds & $27 \%$ \\
Renal abnormalities & $27 \%$ \\
Coarctation of aorta & $10 \%$ \\
Hypothyroidism & $8 \%$ \\
\hline
\end{tabular}

"Modified from Hall et al. (1982) with additional features from Palmer \& Reichmann (1976).

resolves in childhood is seen in $80 \%$ of newborns with Turner syndrome (Hall et al. 1982). Recurrent lymphedema of the extremities is seen in some patients and may be exacerbated by estrogen therapy (Hall 1987). Lymphedema in Turner syndrome is almost always secondary to congenital hypoplasia of the lymphatic channels, although there may be similar lymphatic defects with and without lymphedema (Hall et al. 1982, Vittay et al. 1980). It is unclear why this patient's lymphedema spared her right upper extremity, but the lymph drainage of the right upper extremity is via the right lymphatic duct, whereas the other three extremities and the mesenteric lymphatics drain via the thoracic duct. Aplasia or hypoplasia of the thoracic duct at its junction with the left subclavian vein is, therefore, a possible explanation for her clinical findings. The development of chylous ascites at age twenty-five might have been due to rupture of dilated lymphatics on the serosal surface of the intestine.

A variety of arteriovenous vascular anomalies have been described in Turner syndrome. The most common malformation is coarctation of the aorta, which may occur in as many as $15 \%$ of patients with Turner syndrome, and as many as $50 \%$ of patients with a pure $45, \mathrm{X}$ karyotype. The coarctation is, however, not always hemodynamically significant (Nora et al. 1974, Ferguson-Smith 1965). Less common malformations include aortic valve disease, pulmonic stenosis, ventricular septal defects, atrial septal defects, dextrocardia, hypoplastic left heart and anomalous pulmonary venous return (Lebecque et al. 1984, Price \& Willey 1980). There is an increased incidence of multiple renal arteries over the general population (Hall et al. 1982). Right aortic arch, as noted in this patient, has been described in association with Turner syndrome (Price \& Schicken 1974). In addition, this patient had unusual venous anatomy; although venous insufficiency could have contributed to her lower extremity edema or even to her ascites, a venogram demonstrated free flow of the contrast dye, without evidence of obstruction.

Vascular malformations including intestinal telangiectasia, varicosities, and hemangiomas may be present in patients with Turner syndrome and may result in gastrointestinal bleeding (Reinhart et al. 1983). Lymphagiectasia has also been described with associated protein-losing enteropathy, but these cases have not been associated with chylous ascites, presumably because the lymphatic leakage occurs into the intestinal lumen rather than the peritoneum (Rutlin et al. 1981). Other etiologies for chylous ascites include tuberculous, parasitic, neoplastic, or traumatic obstruction of the lymphatics, intestinal obstruction, portal vein obstruction, and mesenteric adenitis (Press et al. 1982, Kelley \& Butt 1960). There was no evidence for any of these conditions in this patient; though she had a previous history of tuberculosis, the low protein of the fluid and the negative cultures mitigate against a diagnosis of tuberculous peritonitis. 
There have been numerous reports of the use of peritoneo-venous shunts in the treatment of chylous ascites, particularly in children. In 1934, Wegner reported the successful treatment of congenital chylous ascites using a sapheno-peritoneal shunt, termed Routte's operation (Wegner 1934). LeVeen described the use of a prosthetic peritoneovenous shunt for the treatment of ascites associated with cirrhosis in 1974 (LeVeen et al. 1974). Since the introduction of the LeVeen and Denver shunts, there have been numerous reports of their use in the treatment of chylous ascites with variable success. Chang in 1980 described the successful use of a Denver shunt in treatment of chylous ascites due to lymphangiomatosis, and others have reported its use in the treatment of iatrogenic and neoplastic chylous ascites (Chang et al. 1980, Guttman et al. 1982). The complications of these shunts include obstruction, disseminated intravascular coagulation, and infection, and the etiology of the chylous ascites probably influences their success (Press et al. 1982). The use of these shunts in the treatment of chylous ascites remains controversial because of complications and limited long term effectiveness.

\section{Acknowledgments}

F. S. C. acknowledges with gratitude support from the Hartford Foundation.

\section{References}

Chang, J. H. T., J. Newkirk, G. Carlton, J. D. Miller \& E. Orsini (1980). Generalized lymphangiomatosis with chylous ascites. Treatment by peritoneo-venous shunting. J. Pediatr. Surg. 16, 748-750.

Ferguson-Smith, M. (1965). Karyotype-phenotype correlations in gonadal dysgenesis and their bearing on the pathogenesis of malformations. J. Med. Genet. 2, 142-154.

Ford, C. E., K. W. Jones, P. E. Polani, C. De Almeida \& J. H. Briggs (1959). A sex chromo- somal anomaly in a case of gonadal dysgenesis (Turner's syndrome). Lancet 1, 711-713.

Guttman, F. M., P. Montupet \& R. S. Bloss (1982). Experience with peritoneo-venous shunting for chylous ascites in infants and children. J. Pediatr. Surg. 17, 368-372.

Hall, J. G., V. P. Sybert, R. A. Williamson, N. L. Fisher \& S. D. Reed (1982). Turner's syndromeClinical Genetics Conference, Children's Orthopedic Hospital and Medical Center, Seattle and University of Washington (Specialty Conference) West. J. Med. 137, 32-44.

Hall, J. G. (1987). Turner syndrome. In The Genetic Basis of Common Disease. R. A. King, J. I. Rotter \& A. Motulsky (eds). New York, McGraw-Hill (in press).

Kelley, M. L. \& H. R. Butt (1960). Chylous ascites: An analysis of its etiology. Gastroenterology 39, 161-170.

Lebecque, P., G. Bosi, J. Lintermans, M. Stijns, J. Germanes, C. H. Chalant \& A. Vliers (1984). Myxomatous degeneration of the mitral valve in a child with Turner's syndrome and partial anomalous pulmonary venous return. Eur. $J$. Pediatr. 141, 228-230.

LeVeen, H. H., G. Christoudias, M. Ip, R. Luft, G. Falk \& S. Grosberg (1974). Peritoneo-venous shunting for ascites. Ann. Surg. 180, 580-591.

Nora, J. J., A. H. Nora, A. K. Sinha, R. D. Spangler \& H. A. Lubs (1974). The UllrichNoonan Syndrome (Tumer phenotype). Am. $J$. Dis. Child. 127, 48-55.

Palmer, C. G. \& A. Reichmann (1976). Chromosomal and clinical findings in 110 females with Turner syndrome. Hum. Genet. 35, 35-49.

Press, O. W., N. O. Press \& S. D. Kaufmann (1982). Evaluation and management of chylous ascites. Ann. Int. Med. 96, 358-364.

Price, H. L. \& R. M. Schicken (1974). Right aortic arch with coarctation of the aorta. Chest 65, 110-112.

Price, W. H. \& R. F. Willey (1980). Partial anomalous puimonary venous drainage in two patients with Turner's syndrome. J. Med. Genet. 17, 133-134.

Reinhart, W. H., C. Mordasini, M. Staubli \& U. Schuerer (1983). Abnormalities of gut vessels in Turner's syndrome. Postgrad. Med. J. 59, 122-124.

Rutlin, E., F. Wisloff, J. Myren \& A. SerckHanssen (1981). Intestinal telangiectasia in Turner's syndrome. Endoscopy 13, 86-87.

Turner, H. H. (1938). A syndrome of infantilism, congenital webbed neck and cubitus valgus. Endocrinology 23, 566-578. 
Vittay, P., P. Bosze, M. Gaal \& J. Laszlo (1980). Lymph vessel defects in patients with ovarian dysgenesis. Clin. Genet. 18, 387-391.

Wegner, E. S. (1934). Congenital chylous ascites. Am. J. Dis. Child. 47, 586-590.

Wiikins, L. \& W. Fleischmann (1944). Ovarian agenesis: pathology, associated clinical symptoms and the bearing on the theories of sex differentiation. J. Clin. Endocrinol. 4, 357-375.
Address:

Francis S. Collins, M. D., Ph. D.

Departments of Internal Medicine and Human Genetics 4708 Medical Sciences II, Box 0618

University of Michigan Medical School Ann Arbor, MI 48109-0618

USA 